This is an Accepted Manuscript of an article published by Taylor \& Francis in Journal of Contemporary Archaeology, 2017, available online:

http://www.tandfonline.com/10.1558/jca.32442.

Towards a Post-anthropocentric Speculative Archaeology (through Design)

Ola Ståhl

ola.stahl@1nu.se

Linnaeus University, Sweden

Mathilda Tham

mathilda.tham@lnu.se

Linnaeus University, Sweden

With visual commentary by

Cornelius Holtorf

cornelius.holtorf@lnu.se

Linnaeus University, Sweden

\title{
Introduction
}

As disciplines and practices, archaeology and design stand in an interesting relationship to one another. Whereas it is the business of designers to construct universes that can sustain life (or, as we shall see, destroy life), it is the business of archaeologists, in the traditional sense of the word, to look at the remnants of those universes and the traces of those who populated them in order to 
understand the past and the ways in which it resonates in the present and in our conception of our possible futures.

This leads us to pose the following question: if an intimate relationship can be located at the interstitial space between archaeology and design, what might happen if we were to construct transversal lines between and across these disciplines?

Our take on creative archaeology is thus to propose a speculative/fictional space for precisely such transversal lines. It is our contention that this transdisciplinary space, and the extended epistemology that speculation affords, may open up to new creative-critical engagements with our present era - one which geologists increasingly tend to refer to as the Anthropocene, that is, a time period following the Holocene defined by the impact of humanity the Anthropos of the Anthropocene - on the geological strata of the planet. ${ }^{1}$

Design of course, is closely linked to the Anthropocene. Following the industrial revolution, a crescendo of design "ingenuity" - implicit or explicit in steam engines, industrialised agriculture, aeroplanes, mass production and mass consumption - extended humanity's radius of action in time and space to the degree that it transcended the boundaries of ecological systems. The consequences of this, in many ways, are the conditions we face in the Anthropocene.

Hence, if design in the industrial period served to manipulate behaviours, habits, bodies and norms to support development and economic growth, primarily within the confines of industrial capitalism, and to assure the continuous reproduction of systems based on the

\footnotetext{
${ }^{1}$ Although the concept of the Anthropocene is increasingly accepted, it should be noted that the periodization it entails remains under debate (see, for instance, Ruddiman 2003; Crutzen 2007; Smith and Zeder 2013).
} 
exploitation of natural and human resources, increasingly there is now a call for design to address the needs this historical process has spawned. In the face of the ecological crisis, ${ }^{2}$ which converges with socio-cultural, political and economic unrest, design facing the Anthropocene is called upon to reorient itself to support futures of sustainability, to leave the remit of products and instead act as facilitator for change towards ways of living in and beyond the Anthropocene. Designers are called upon to work speculatively to propose new ways of being, doing and thinking, to construct micro-universes in which life, in some form, can be reinvented and sustained, and to open up creative-critical perspectives to afford glimpses of other paradigms than those currently dominant. ${ }^{3}$

Archaeology stands in a different relationship to the Anthropocene. As Matt Edgeworth has pointed out, archaeology provides anyone interested in engaging with the Anthropocene with "a large body of material evidence, in the form of the archaeological record, against which specific arguments can be checked and evaluated" (Edgeworth 2014, 75). As such, archaeology and archaeology's understanding of the world should be a significant part of any inter-, multi- or transdisciplinary approach to sustainability and the Anthropocene. ${ }^{4}$

\footnotetext{
${ }^{2}$ See, for instance, Intergovernmental Panel on Climate Change 2015.

${ }^{3}$ In particular, so-called "emerging” design practices such as critical and speculative design, design fictions, metadesign, social design and transdisciplinary design. However, the term "emerging" here is something of a misnomer, as these are practices that reach back into design history as well as the history of other disciplines such as architecture, literature, cinema and art.

${ }^{4}$ In "The Anthropocene and Transdisciplinarity" (Kelly 2014), James M. Kelly points out the value of transdisciplinary approaches to the issues raised by the Anthropocene. In his introduction to the same forum, Matt Edgeworth describes the concept as a "catalyst for the setting up of interdisciplinary research projects"
} 
However, archaeology, like many other disciplines, in its encounter with the Anthropocene comes up against a set of limitations in the period's implicit, and at times explicit, anthropocentrism. This means that its materials tend to be evaluated and interpreted vertically, as if from above, from a perspective providing historical narratives and frameworks that often function to legitimise particular sets of practices and knowledges. Consequently, archaeology, as much as design, is called upon to reinvent itself in light of the crises we now face. Such intentions seem evident, to us, in Ewa Domànska's proposition that archaeology must now become not only "a critical discourse and a transformative discipline", but also

a space of cross-epistemological research and advocacy of alternative ways of thinking about heritage, subjectivity, personhood, identity, relations between humans and non-humans, materiality, environment, non-intentional agency, indigeneity, the sacred, tradition, etc. (Domanska 2014, 100)

Similarly, we see in Matt Edgeworth's suggestion that we turn to "speculative realism" another attempt to re-think archaeology beyond the confines of the correlationism (i.e. object-oriented ontologies) that in many ways reside at the very core of the anthropocentrism of the Anthropocene (Edgeworth 2016). Another point of entry is suggested by Zoe Crossland, who speaks of archaeological traces as "portents [that] evoke a feeling of potential, material signs deployed to cultivate a disposition toward the future" (Crossland 2016, 127).

(Edgeworth 2014). However, while we fully concur that the Anthropocene demands approaches that exceed current disciplinary boundaries, we would like to emphasise that these approaches also need to transgress the hegemonic boundary between artistic and creative approaches and theoretical and critical ones. 
It seems to us that design and archaeology are both undergoing a transition prompted by the challenge of the Anthropocene - a challenge that calls for transdisciplinary approaches and extended epistemologies, including speculative ones that allow us to engage with what it might come to mean to live in and beyond the Anthropocene.

We, two designer-researchers, therefore reinvent ourselves as post-anthropocentric, speculative archaeologists. We are (naively/earnestly) approaching archaeology as a study not of beginnings but of new beginnings in a future threshold between the Anthropocene and the PostAnthropocene. In doing so, we are transporting our alter-selves to this speculative excavation site, to gently dig, brush, sense traces of other socio-material relations - such that evidence a disruption of the deeply rooted power dynamics of the Anthropocene. ${ }^{5}$

\section{The Beginning of the Excursion}

The two archaeologists don their sixth-sense suits, lay down at the excavation site, an urban prairie of wild-flower meadows and emerging ecologies of larval species. They grab each other's shoulders, embrace, close their eyes, take three deep breaths and meditate, abandoning the confines of their gendered bodies. The dermis that cushions the interior of their bodies is gradually compromised, the barrier of the epidermis opens up to the external environment and its ecologies. The organisation of their bodies shift, the structure of organs alters. The vertical

\footnotetext{
${ }^{5}$ A disclaimer may be appropriate at this point: we know, of course, that we, as all, suffer from paradigmatic blindness, or a Stockholm Syndrome where we are complicit in the range of co-atrocities of the supremely privileged even before breakfast. Yet, we are drawing on what may be termed weak signs or whispers today, as well as those from the past, to propose a transdisciplinary convergence of archaeology, speculation and design fiction.
} 
hierarchy of sensations collapses. They become flat, horizontal, aligned with the geosphere. There is a violence, a gentle one, involved in the ritual of post-anthropocentric archaeology, a displacement of the territories that bind our bodies and sensations to given territories and coordinates. It is a ritual of undoing and unbinding, gradually loosening the knots of the organised body, allowing flows of intensities to pass, unexpected encounters opening up processes of poiesis and fictioning that generate veritable plethora of universes - past, present and future.

As the two archaeologists allow themselves to float back through time, future trajectories emerge, shooting off into the distance. The sweet scent of flowers blends with the sharp olfactory note of petrol, a varied bird and insect chorus is drowned by bleeps of a million mobile phones. Temporalities coincide in complex simultaneity. Now they sense the myriad of life that lies before and after their presence. They start caressing the space, filtering each molecule. Each finding is held for a moment, like the holding of a precious bird, its essence multi-sensorially recorded, contained as a trace for the archives, then released with a breath of "thank you".

\section{Exhibit One}

Scraps of candle wax, charred wood, pieces of felt tarnished with fat, twisted shards of metal and other debris, a variety of artefacts in conditions less than pristine, whiffs of smoke, sound of solemn voices.

The archaeologists gather the traces, placing items, images, sounds, smells and feelings in different constellations, drawing lines between them, intersecting at different points. What 
fictions emerge at the points of intersection? These are traces, they contend, of a people - the Anthropos, the culture of which is the subject of their study - performing a ritual. A cloaked figure on the balustrade, another one squatting beneath; some lying still on the bare ground, others standing. The image jerks, shifts, a clearing now; three of them dressed in t-shirts and jeans, baseball caps, standing in a triangular formation. What is being acted out in these ceremonies? The archaeologists detect an air of melancholy in the silence that saturates the scenes they witness. The very figure of the Anthropos is a melancholy one. Its detached, cold rationality came at the cost of the loss of a sense of systemic interconnectedness with the geosphere. This is the melancholy of the Anthropos: a repressed sense of melancholy caused by the loss of all senses of embeddedness and embodiedness.

But there is something else going on in and between the constellations of traces they study, an openly manifested mourning, paradoxically caused by the Anthropos distancing itself from the melancholic condition of its culture; or better, perhaps, a process of mourning caused by the Anthropos revolutionary becoming-other to itself, a becoming that stretches beyond the confines of anthropocentrism. This process of mourning provides a framework for the giving up on one's self. In this way, the ritual demarcation of loss is the construction of a space for gratitude, disappointment, grief; a space required for the community to mobilise energy for the revolutionary shift they stand before, ceremonial "loving and leaving" rituals required for the abandoning of non-life-viable artefacts, habits, lifestyles, dreams, nightmares, relationships, processes, industries, languages and worldviews.

They are not mourning the revolution, nor the lack of a revolution; they are mourning in order to give space for the revolution. 


\section{Exhibit Two}

Mediated images: mass graves; scorched earth; oil spills, water black as tar; mushroom-shaped clouds in the distance; masses of people waiting to cross a border, groups of soldiers smoking at the side lines; fascist vigilantes charging at protesters; neon light in the rain, a permanent bombardment of advertisements for soft drinks, cars, beauty products, plastic surgery, whitening of skin and teeth from columns of massive screens.

As the images continue to flicker by, the two archaeologists attempt to make connections between them. What the images bring to mind, initially, is the way in which material artefacts, environments, technologies, images and languages function as a form of manipulation; the way in which they sanction or forbid certain actions and forms of embodiment. The sequences of mediated images and the occurrences, events and practices they depict now appear to be vibrant manifestations of specific constellations of power configured around gender, race, ethnicity, sexuality, class; territorialities that structure the distribution of economic, social, cultural and political privilege in the Anthropocene. In and between the images, the norms that govern the life of the Anthropos begin to materialise; patriarchal, heteronormative and racist structures of domination, repression and exploitation. What emerges before them are image sequences of interconnected systems in collapse, one after the other. The culture of the Anthropos is one that constantly verges on collapse. Permanent crisis is what defines it as a culture, feverishly driving it to the point of extinction.

What leaves the two archaeologists perplexed is how a culture founded entirely upon inequality and exploitation could subsist. The two archaeologists know that in the culture of the 
Anthropos there was a medical procedure known as anaesthesia. The material at their disposal shows that this explicit practice, to remove sensation, was not only practiced within medicine. Much rather, it was a deeply engrained cultural practice of the socio-political and economic epicentres of the Anthropocene. A general public was able to suppress whispers or even shouts of suffering from other species, other humans - and even from themselves. They were able to divide themselves into body and mind, and even develop a cognitive dissonance by the means of which they could hold different, even contrasting value systems at once. Such culture of anaesthesia was required for the conditions of the Anthropocene to be continually reproduced in spite of the inequalities and contradictions they spawned. Imagine the contortion, imagine the strategic schooling of subjects over long periods of time that it must have taken to make this possible.

\section{Exhibit Three}

Fluffy material, remnants with string attached; a pendulum made from braided hemp and cotton wool; a string with feathers attached to it.

Are these tools, instruments for investigation and exploration? Some fluff and a string - within the context of the culture of the Anthropos, this seems useless. This is a culture characterised by digging, the spade, a patriarchal notion of exploration as colonisation and a logic of conquering. What place does the cotton pendulum have within the context of such culture? What are the fictions of these items? At what points do they intersect? 
It seems clear to the two archaeologists that at some point, something must have occurred that prompted a shift within the hegemonic culture of the Anthropos; a shift towards the development of other sensibilities than those that characterised the Anthropos - or, in other words, a turn from the anaesthesia of the Anthropocene towards a new sense of aesthesis. This turn seems to be a pronounced feature of the ontogenesis of post-anthropocentric subjectivity. Could the instruments and tools in the exhibit have played a part in the development of such new sensibilities? Were they tools of attentiveness that taught the subject of the Anthropos to listen, look, smell, taste, sense, think, speak, act in a different way?

The two archaeologists find vague traces of this shift dispersed globally, and grouping the traces together, a tendency materialises: a turn towards a holistic and systemic attentiveness to the different ecologies of the geosphere. In this turn from anaesthesis to aesthesis, it seems the cultural hegemony of the Anthropos was gradually compromised. Evidences of its collapse were ample among their findings, and within the ruptures and cracks emerged new ethico-aesthetic trajectories focusing less on morals, legislation and authority and more on pleasure, love and care. This ethico-aesthetic of the post-anthropocentric subject emerged as a radical and transversal trajectory intimately weaving together knowledges and practices that within anthropocentrism had been considered apart from, even opposed to, one another: ethics, aesthetics, politics, creativity, pleasure, care, love.

\section{Exhibit 4}

Some writing preserved, chiselled into a slab of granite. Yet the font, Pingweb vs23 light, reveals this to be of the computer age. The inscription: "We hereby promise to always guard the 
supreme right and responsibility of taking risks, venturing off into lands of danger and

impropriety. Our future societies shall thrive on flying in the dark, taking leaps of faith, pursuing dreams, revel in the absurd and the carnivalesque - and in sharing. Ze who has never lost face must be offered group-counselling." The slab was signed: "Transdesign for Impropriety and Risk".

From the material the two archaeologists had previously gathered, it appears as if different forms of transversal and transdisciplinary self-organization had materialized at approximately the same time across the globe in different institutions and practices: within multinational corporations and among local businesses, within government and municipal institutions and within the cultural industries, within the learning institutions and academies and among factory and assembly-line workers, among the clergy in churches, mosques and temples and among groups of political activists. Across disciplines and practices previously kept at a distance from one another, something began to crystalise, a seed or small kernel which soon became a germinal, mutagenetic point from which transversal and transdisciplinary trajectories of change emerged. The dominant power structures of the culture of the Anthropos began to appear hollow and brittle, supported merely by violence and repression. Opposed to such structures of repression, self-organised networks began to emerge based on solidarity and collectivity, and the affirmation of difference and desire for change.

Such transformation takes courage; it requires a leap of faith, a willingness to collectively accept risk. Keeping the etymology of the word "risk" in mind, it has to do with danger and, significantly, with impropriety. What is the meaning of impropriety within the context of the culture of the Anthropos? Improper to what and to whom? The word "proper" shares a history 
with words such as "private" and "property". Its etymology is lodged deep within the notion of the autonomous, individual self. ${ }^{6}$ Only later did it come to be associated with a particular kind of conduct. Is this perhaps the meaning of danger and impropriety in this context? A notion of risk very different from the anthropocentric narratives of the riskiness of stock markets and venture capitalists, one that has to do with the abandonment of the individual self of the Anthropos in favour of an improper, post-anthropocentric subjectivity that, at the time, they knew nothing about? What does this improper subject look like? What does it eat? How does it sleep (does it sleep)? How does it love, sense, taste, smell? How does it form communities? Taking a leap into this unchartered territory must have required faith, and must have involved both danger and risk.

\section{The End of the Excursion}

Dizzily, the two archaeologists wake up on the wild-flower prairie. Standing on their heads, they let the many pockets of the six-sense suits unfold manifold expressions into a floaty dance. Now, as they invite others to join a game of cat's cradle amongst the threads of fictions and knowledges that imagery, scents, sounds, touches, atmospheres form, these feel remarkably familiar and remarkably different - prosaic, banal and magical simultaneously. "Ah, but we are upside down!", they exclaim to each other. Power has truly shifted.

\section{Post/Prescript}

This exploration has been emergent, unruly, idiosyncratic and, for us, filled with discoveries. On this particular expedition, as these particular personas, we attempted to draw transversal lines between two disciplines (one which we know, and one towards which we turn gingerly) and

\footnotetext{
${ }^{6}$ See pro privo, for the individual, privus, one's own, individual.
} 
between knowing from theory, from work and life experience, and from dreaming or imagining. This allowed for a defamiliarisation (see Fager 2017) from the life and universes in which we are immersed; and, in turn, it may open up to a future refamiliarization where we come to inhabit our universes slightly differently. It is our contention that a creative archaeology such as the one we're proposing, offers an understanding of the world and the impasse we're currently facing that has something significant to contribute to such transdisciplinary refamiliarisation in that it opens up a space that is at once speculative, creative and critical and that allows us to operate across different scales (artefacts, systems, paradigms) and temporalities (a set of presents and pasts, but also near-futures and far-futures).

Now, were we to organize the multitude of impressions and encounters of our transdisciplinary expedition into themes, they may be the following: first, a ritualized mourning of past ways of life to create space for new such; second, the crystallization of many-layered alienations as anaesthesia; third, the celebration of ethico-aesthetics for an alternative deep attentiveness or love; and fourth, the elevation of risk-taking to enable a horizontal and vertical permeation of societal structures

The remnants of rituals, the mediated images of a culture of anaesthesia, the tools and technologies of new modes of becoming, traces of a transversal revolutionary movement - these objects, images and artefacts are speculative fictions, but they are also, and simultaneously, real in that they create fragments of "new" or "other" universes in the world as they emerge on these pages. Engaging speculatively, creatively and critically with the world, we have the potential to open up to ethico-aesthetic trajectories that allow us to think ourselves, each other and the complex of ecologies we inhabit, differently. What we bring back, or forth, from this venture into the transdisciplinary, creative-critical space between archaeology, design and speculation, 
then, is not a greater clarity about our futures, but some tuning of our understanding of our present. Perhaps the themes presented here are to be considered seeds worthy of cultivation here and now.

\section{On resilience and Archaeological Futures (A Visual Commentary on Ståhl and Tham)} Cornelius Holtorf

[image: Ai Weiwei, Dropping a Han Dynasty Urn. 1995.]

Sustainability is about the endurance of systems and processes. Sustainability can be achieved through resilience. Resilience is the ability of a system or process to absorb disturbance. This series of three photographs (Figure 1) is a commentary on archaeological sustainability. What Ai Weiwei tells us through these images (if not in these images) is that the archaeologist does not necessarily need to be sorry for loss of archaeological matter, aka archaeological heritage. The vase proved to be resilient because it lives on in human culture, despite - and indeed because - it did not physically survive unharmed. Anthropocentric this thought may be but what is in the human interest should be in our interest. Principles of care, caution and love can be enacted through other practices than those involving preservation of the status quo. We may care for Homo sapiens in the same way we care for our children: we want them to develop and thrive while proactively taking calculated risks, continuously able and keen to adapt to changing circumstances. Dropping an ancient Chinese urn may be done by a child or by an artist. In any case, the moment caught in the middle picture, represents the moment of transformation of a collection item into something else: an object of art, of change, translated into the cultural 
language of another age and society. Dropping an artefact, transforming an object into its traces, can add value: cultural, social, economic. Dropping an urn can create significance in a new world, a world that has little patience with urns collected and stored in archives. The drop is not only a material collapse but also a transformative renewal of an object previously associated with a time that was before into an object associated with a time to come. This urn dropped by $\mathrm{Ai}$ Weiwei has not been lost to human society and to archaeology (although it might have been lost if he hadn't dropped it); rather, it is the token of an archaeological future cultivated here and now - a sustainable archaeological future beyond preservation.

\section{References}

Crossland, Z., 2016. “The Anthropocene: Locating Agency, Imagining the Future.” Journal of Contemporary Archaeology.: 1 (1): 123-128.

Crutzen, P. J., W. Steffen and J. R. and McNeill. 2007. "The Anthropocene: Are Humans Now Overwhelming the Great Forces of Nature?" Ambio 36 (8): 614-621.

Domanska, E., 2014. “The New Age of the Anthropocene.” Journal of Contemporary Archaeology 1 (1): 96-101.

Edgeworth, M., 2014. “Archaeology of the Anthropocene.” Journal of Contemporary Archaeology 1 (1): 73-77.

2016. "Grounded Objects: Archaeology and Speculative Realism." Archaeological Dialogues 23 (1): 93-113.

Fager, L., 2017. Split Vision: En studie av designprocessen som lärprocess $i$ ett utbildningssammanhang. Licentiate Diss, Umeå University, Faculty of Arts, Department of Creative Studies. 
Kelly, J. M., 2014. "The Anthropocene and Transdisciplinarity." Journal of Contemporary Archaeology 1 (1): 91-96.

Ruddiman, W. F., 2003. "The Anthropogenic Greenhouse Era Began Thousands of Years Ago.” Climatic Change 61 (3): 261-293.

Smith, B. D. and Zeder, M. A., 2013. "The Onset of the Anthropocene.” Anthropocene. 4: 8-13.

Ola Ståhl is Senior Lecturer and Deputy Head of the Department of Design, Linnaeus University, Sweden. Address for correspondence: Department of Design, Linnaeus University, Linnéuniversitetet, Box 451, 35106 Växjö, Sweden.

Mathilda Tham is Professor in Design at Linnaeus University, Sweden. Address for correspondence: Department of Design, Linnaeus University, Linnéuniversitetet, Box 451, 351 06 Växjö, Sweden.

Cornelius Holtorf is Professor in the Department of Cultural Sciences, Linnaeus University, Sweden. Address for correspondence: Department of Cultural Sciences, Linnaeus University, Linnéuniversitetet, Box 451, 35106 Växjö, Sweden. 